\title{
The Role of cAMP Response Element-Binding Protein in Estrogen Negative Feedback Control of Gonadotropin-Releasing Hormone Neurons
}

\author{
Andrea Kwakowsky, Allan E. Herbison, and István M. Ábrahám \\ Centre for Neuroendocrinology and Department of Physiology, Otago School of Medical Sciences, University of Otago, 9054 Dunedin, New Zealand
}

The mechanisms through which estradiol (E2) regulates gonadotropin-releasing hormone (GnRH) neurons to control fertility are unclear. Previous studies have demonstrated that E2 rapidly phosphorylates cAMP response element-binding protein (CREB) in GnRH neurons in vivo. In the present study, we used GnRH neuron-specific CREB-deleted mutant mice [GnRH-CREB knock-outs (KOs)] with and without global cAMP response element modulator (CREM) deletion (global-CREM KOs) to investigate the role of CREB in estrogen negative feedback on GnRH neurons. Evaluation of GnRH-CREB KO mice with and without global CREM deletion revealed normal puberty onset. Although estrus cycle length in adults was the same in controls and knock-out mice, cycles in mutant mice consisted of significantly longer periods of diestrus and less estrus. In GnRH-CREB KO mice, basal levels of luteinizing hormone (LH) and the postovariectomy increment in $\mathrm{LH}$ were normal, but the ability of $\mathrm{E} 2$ to rapidly suppress $\mathrm{LH}$ was significantly blunted. In contrast, basal and postovariectomy LH levels were abnormal in GnRH-CREB KO/global-CREM KO mice. Fecundity studies showed that GnRH-CREB KO with and without global CREM deletion were normal up to $\sim 9$ months of age, at which time they became prematurely reproductively senescent. Morphological analysis of GnRH neurons revealed a significant reduction $(p<0.01)$ in GnRH somatic spine density of GnRH-CREB KO mice compared to control females. These observations implicate CREB within the GnRH neuron as an important target for E2's negative feedback actions. They also indicate that the rapid modulation of CREB by E2 is of physiological significance in the CNS.

\section{Introduction}

In addition to mediating its effects through direct nuclear estrogen receptors (ERs), estradiol (E2) has rapid, nonclassical actions via the activation of second messenger molecules such as extracellular signal regulated kinase $1 / 2$, protein kinase $A$, and transcription factors such as cAMP response element-binding protein (CREB) (Nilsson et al., 2001; Abrahám and Herbison, 2005; Vasudevan and Pfaff, 2008; Micevych and Dominguez, 2009). Although recent studies have demonstrated the possible role of rapid nonclassical estrogen signaling in reproduction, sexual behavior, and nociception (Dewing et al., 2007; McDevitt et al., 2008; Boulware and Mermelstein, 2009; Herbison, 2009; Kelly and Rønnekleiv, 2009), the physiological significance of rapid estrogen actions through transcription factors such as CREB remain unknown.

The gonadotropin-releasing hormone ( $\mathrm{GnRH}$ ) neurons represent the key output cells of the neural neuronal network regu-

\footnotetext{
Received March 18, 2012; revised June 22, 2012; accepted June 28, 2012.

Author contributions: A.K., A.E.H., and I.M.A. designed research; A.K. performed research; A.K., A.E.H., and I.M.A. wrote the paper.

This work was supported by the Marsden Fund, the Otago School of Medical Sciences, and the Department of Physiology of the University of Otago. We acknowledge the excellent work of the members of the Hercus Taieri Resource Unit, University of Otago. We thank Dr. Theo Mantamadiotis (Victorian College of Pharmacy, Monash University, Victoria, Australia) for the generous provision of the CREB-loxP and CREM knock-out mice.

Correspondence should be addressed to Dr. István M. Ábrahám, Centre for Neuroendocrinology and Department of Physiology, University of Otago, Lindo Ferguson Building, 270 Great King Street, P.O. Box 913, 9054 Dunedin, New Zealand. E-mail: istvan.abraham@otago.ac.nz.

DOI:10.1523/JNEUROSCI.1333-12.2012

Copyright $\odot 2012$ the authors $\quad 0270-6474 / 12 / 3211309-09 \$ 15.00 / 0$
}

lating fertility. Gonadal steroid hormones such as E2 provide one of the most important homeostatic modulators of GnRH neuronal function in mammalian species (Herbison, 2006; Moenter et al., 2009). In addition to direct genomic effects, E2 also exerts "nonclassical" actions to modulate the activity of GnRH neurons and, in particular, bring about estrogen negative feedback (Glidewell-Kenney et al., 2007). The mechanisms underlying these nonclassical actions have been probed by examining the effects of rapid E2, unlikely to involve transcriptional responses, on adult GnRH neurons (Herbison 2009; Kelly and Rønnekleiv, 2009; Moenter and Chu, 2012). Such studies have identified acute actions of E2 on GnRH neuron excitability (Kelly et al., 1976; Chu et al., 2009) and a range of effects on calcium dynamics, kinases, and transcription factors such CREB (Abrahám et al., 2003, 2004; Romano et al., 2008; Herbison, 2009; Zhao et al., 2009). The key issue that remains to be established is what importance and functional relevance these range of nonclassical E2 actions have on estrogen feedback mechanisms in vivo.

Given previous work showing that rapid E2 acutely phosphorylates CREB in GnRH neurons of adult female mice in vivo (Abrahám et al., 2003), we have generated here female mice with a GnRH neuron-specific CREB deletion. Because, cAMP response element modulator (CREM) has been found to be able to compensate for CREB deletion in other brain regions (Rudolph et al., 1998; Mantamadiotis et al., 2002), we generated GnRH neuron-specific CREB deletions on both normal and CREM global knock-out (KO) backgrounds. Together, these studies identify CREB as an important signaling molecule in $\mathrm{GnRH}$ 
neurons that is essential for normal estrogen negative feedback in vivo.

\section{Materials and Methods}

Animals. All experiments were approved and performed in accordance with the regulations of the Australian and New Zealand Council for the Care of Animals in Research and Teaching and the University of Otago Animal Ethics Committee. All mice were bred and housed at the University of Otago Hercus Taieri Resource Unit. The animals were maintained under conditions of a $12 \mathrm{~h}$ light/dark cycle (lights on at 7:00 A.M.) with food and water available ad libitum. All experiments were performed on female mice. Six mouse lines were used: C57BL/6 wild-type control (C57BL/ 6); $C R E B^{\text {loxP/loxP }}$ control (CREB loxP/loxP $^{2}$; GnRHCre;CREB ${ }^{\text {loxP } / \text { loxP }}$ $(\mathrm{GnRH}-\mathrm{CREB} \mathrm{KO}) ; \mathrm{CREM}^{+/+}$control $\left(\mathrm{CREM}^{+/+}\right) ; \mathrm{CREM}^{-/-}$(globalCREM KO); GnRHCre;CREB ${ }^{\text {loxP/loxP }}$;CREM ${ }^{-/-}$(GnRH-CREB KO/ global-CREM KO). CREM ${ }^{+/+}$controls were the wild-type littermates from CREM heterozygous crossings.

Previous studies with the GnRH-Cre line demonstrated strong GnRH immunoreactivity in 100 of 104 randomly picked CRE-positive cells, and weak staining in the remaining four cells (Yoon et al., 2005). The cross of the GnRH-Cre line to ROSA-26 indicator mice (Srinivas et al., 2001) also verified that the Cre transgene product is functional and efficient (Yoon et al., 2005). Confirmatory studies in our laboratory have shown that Cre is expressed by $97 \pm 2 \%$ of all GnRH neurons, and crossing this line with the ROSA-26 indicator mice (Soriano, 1999) revealed Cre-dependent recombination in $97 \pm 1 \%$ of GnRH neurons (R. E. Campbell, R. Porteous, and A. E. Herbison, unpublished data). Unpublished data show that Cre is expressed from embryonic day 13 in GnRH neurons (J. Shin and R. Campbell, personal communication).

The CREB ${ }^{\text {loxP } / l o x P} C R E M^{+/-}$mouse (provided by T. Mantamadiotis, Monash University, Victoria, Australia) (Mantamadiotis et al., 2002) has exon 10 of the CREB1 allele flanked with loxP sites. Cre-mediated recombination of the CREB1 $1^{\text {loxP }}$ allele leads to a CREB1 null allele that encodes a truncated unstable CREB protein devoid of DNA-binding and dimerization domains. The CREM-mutant line was generated by homologous recombination as described by Blendy et al. (1996). By crossing these transgenic lines, we generated mice in which CREB and/or CREM is deleted from GnRH neurons from the early embryogenesis.

Puberty and estrus cycle. Prepubertal female mice were examined every day for vaginal opening, and once this had occurred, vaginal smears were taken each day (10:00 A.M.) until the first estrus smear was encountered. Two weeks after the first estrus, the estrus cycle was evaluated using vaginal smears for a period of 3 weeks.

Fecundity testing. The fecundity of mice ( $n=6$ of each genotype) was examined by pairing them with wild-type mice for a period of $6-12$ months. The day of birth, number of pups, and delivery intervals were recorded for each pair over this period.

Immunohistochemistry. Free-floating dual-label peroxidase-based immunohistochemistry for phospho-CREB (pCREB) or CREB and GnRH was undertaken as described previously (Abrahám et al., 2003). Briefly, brain sections were incubated with primary antibodies recognizing CREB (1:1000; Cell Signaling Technology) or pCREB (1:200; Cell Signaling Technology). This was followed by biotinylated goat anti-rabbit IgGs (1:200; Vector Laboratories) and the avidin-biotin-HRP complex (1:200; Vector Elite ABC kit, Vector Laboratories) incubations. Labeling was then visualized with nickel-diaminobenzidine tetrahydrochloride (DAB) using glucose oxidase that resulted in a black precipitate within the nucleus of the labeled cell. The sections were then processed further for GnRH immunoreactivity with the LR1 antibody (1:40,000; Dr. R. Benoit, Montréal General Hospital, Montréal, Québec, Canada) followed by incubation with peroxidase-labeled anti-rabbit IgGs and revealed by DAB only to result in a brown precipitate within the cytoplasm. Specificities of the primary antibodies have been tested and reported previously (McNulty et al., 1998; Abrahám et al., 2003). The omission of the primary antibodies resulted in complete absence of the immunoreactivity.

Sections with CREB-GnRH dual-labeling immunohistochemistry were examined under an Olympus BX51 microscope (Olympus Corporation) by an investigator blinded to the experimental groupings. Analysis was undertaken by counting the numbers of single-labeled (brown cytoplasm) and dual-labeled (brown cytoplasm and black nucleus) $\mathrm{GnRH}$ neurons in two coronal brain sections in the regions of the medial septum (MS), rostral preoptic area (rPOA), and anterior hypothalamus (AHA), represented by plates $22-24,25-27$, and $28-31$ of Paxinos and Franklin's (2000) brain atlas. The CREB and pCREB expression in GnRH neurons was calculated as a percentage of $\mathrm{GnRH}$ neurons at each level and also as a percentage of all of the GnRH neurons examined.

GnRH neuron spine density analysis. GnRH immunofluorescence labeling was performed to visualize spine density of GnRH neuron somata using the GA02 antibody (1:1500; a gift from G. Anderson, University of Otago, Dunedin, New Zealand) that labels the somata and proximnal dendrites of GnRH neurons (Rizwan et al., 2012) (Anderson, unpublished results). Brain sections from intact diestrus female $C R E B^{\text {loxP/loxP }}$ and GnRH-CREB KO mice were incubated with the GA02 primary antibody followed by incubation with biotinylated donkey anti-guinea pig IgGs (1:200; Jackson ImmunoResearch) and streptavidin-conjugated Alexa Fluor 488 (1:200; Invitrogen).

Two sections containing the largest number of GnRH neurons from the rPOA were selected from each animal, and each neuron was imaged and analyzed using a Zeiss LSM 710 upright confocal laser-scanning microscope. An argon laser exciting at $488 \mathrm{~nm}$ was used with a $63 \times$ Apochromate objective (numerical aperture, 1.4) and $3 \times$ zoom function. Stacks of images were captured at $400 \mathrm{~nm}$ intervals. For each cell, somatic spines were identified as short cytoplasmic processes emerging from the soma in a 1-5 $\mu \mathrm{m}$ range (Campbell et al., 2005; Chan et al., 2011). Thin protrusions greater in length were filopodia (Campbell et al., 2005). Spine numbers were quantified by analyzing each captured image in $z$-plane using the LSM 710 control software, Zen 2009. Soma circumference was measured in a stack outlining the greatest part of the soma and excluding the proximal dendrite.

Estrogen negative feedback protocol. Adult female mice (10-12 weeks old) of all six genotypes were anesthetized with Avertin $(0.1 \mathrm{ml} / 10 \mathrm{~g}$ body weight) and $50 \mu \mathrm{l}$ tail blood samples collected before bilateral ovariectomy (OVX). Seven days after OVX, mice were anesthetized with Avertin and additional $50 \mu \mathrm{l}$ tail blood samples obtained. Two days later, mice each received a subcutaneous injection of $17-\beta$-estradiol ( $1 \mu \mathrm{g} / 20 \mathrm{~g}$ body weight; Sigma) in sesame oil or vehicle alone, killed $3 \mathrm{~h}$ later by an overdose of Avertin, a blood sample obtained from the right atrium, and the brain perfusion fixed through the heart with $4 \%$ paraformaldehyde solution to enable CREB or pCREB-GnRH dual immunohistochemistry. Blood sera were stored at $-20^{\circ} \mathrm{C}$ until assayed for LH by RIA. Plasma LH concentrations were determined using the anti-rLH-S-11 antiserum and mouse luteinizing hormone reference preparation (mLH-RP) reference provided by A. F. Parlow (National Hormone and Peptide Program, National Institutes of Health, Bethesda, MD). Studies using the negative feedback protocol outlined here have shown that LH levels are low in the intact animals, elevated in 2 week ovariectomized mice, and suppressed at the $3 \mathrm{~h}$ post-E2 time point (Campbell et al., 2011).

Statistical analysis. All data were analyzed by one-way ANOVA followed by Tukey's post hoc test with a value of $p<0.05$ considered significant. Values for each animal were used to determine means, and these were used to generate \pm SEM values for each group. Data in all experiments are expressed as mean \pm SEM. All statistical analyses were performed using Statistica 7.0 (StarSoft) and Prism (version 5.03; GraphPad Software).

\section{Results}

\section{GnRH neuron-specific deletion of CREB}

Dual-label immunohistochemistry in control (C57BL/6, $C R E B^{\text {loxP/loxP }}$, and CREM ${ }^{+/+}$mice) and global-CREM KO mice revealed that $C R E B$ was restricted to the cell nuclei of $\sim 30 \%$ of all GnRH neurons (Fig. $1 A, B$ ). In GnRH-CREB KO and GnRHCREB KO/global-CREM KO mice there was a complete absence of CREB immunoreactivity in GnRH neurons (Fig. $1 A, B$ ), indicating highly efficient Cre recombination in these lines.

The percentage of GnRH neurons expressing pCREB $3 \mathrm{~h}$ after E2 administration in vivo was also examined. In control (as above) and global-CREM KO mice, $\sim 25 \%$ of $\mathrm{GnRH}$ neurons 


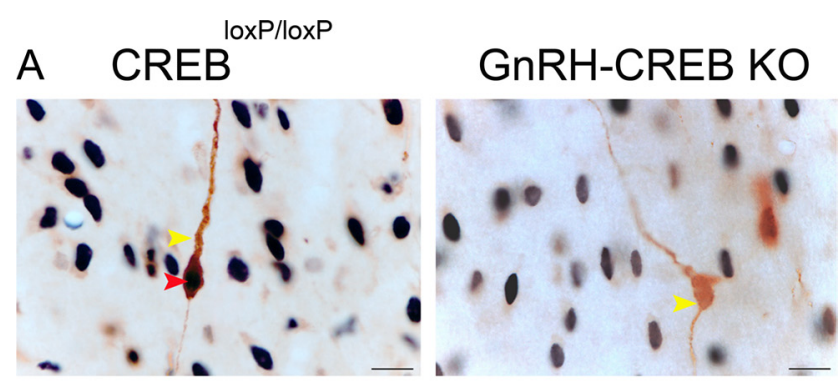

B

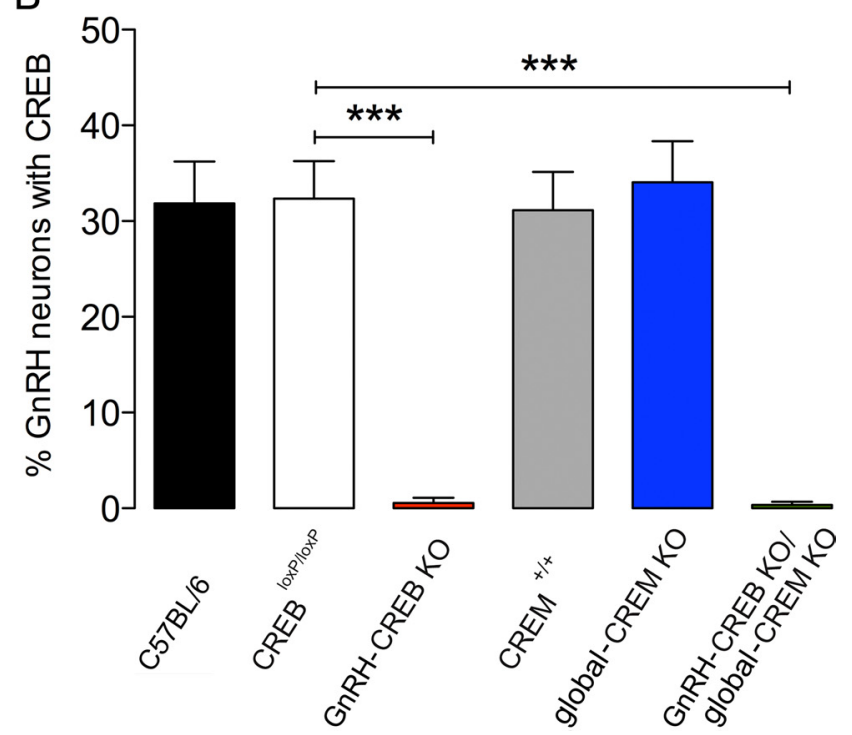

Figure 1. $\quad A$, CREB expression in CREB mutant mouse line. The photomicrographs show nuclear CREB immunoreactivity (black nuclei, red arrowhead) in GnRH neurons (brown cytoplasm, yellow arrowhead) in CREB ${ }^{\text {loxP/loxP }}$ mouse and lack of CREB expression in GnRH neurons (brown cytoplasm, yellow arrowhead) in GnRH-CREB KO mouse. Scale bars, $10 \mu \mathrm{m}$. B, Histogram shows the percentage of GnRH neurons expressing CREB in control ( $\left(57 B L / 6,\left(R E B^{B / x P / l o x P},\left(R E M^{+/+}\right)\right.\right.$, GnRH-CREB KO, global-CREM KO, and GnRH-CREB KO/global-CREM KO mice. The histogram shows the means ( + SEM); $n=7-14 .{ }^{* *} p<0.001$ (ANOVA with Tukey's post hoc test).

$\left(\mathrm{C} 57 \mathrm{BL} / 6,27.6 \pm 2.4 \% ; \mathrm{CREB}^{\text {loxP/loxP }}, 27.7 \pm 1.9 \% \mathrm{CREM}^{+/+}\right.$, $25.9 \pm 3.4 \%$; global-CREM KO, $24.5 \pm 2.7 \% ; n=4-8$ ) showed pCREB immunoreactivity. In contrast, there was no pCREB expression in GnRH neurons in GnRH-CREB KO and GnRHCREB KO/global-CREM KO mice (data not shown).

Increased GnRH neuron number in global CREM KO mice A previous report of global-CREM KO and CREB KO mice showed extensive neuronal cell loss in the brain (Mantamadiotis et al., 2002). To evaluate whether the GnRH neurons survive without CREB and/or CREM, the number of GnRH neurons was counted in the control and mutant mice. The data showed that the numbers of neurons immunoreactive for GnRH between control and GnRH-CREB KO mice were not different (Table 1). In contrast, significantly more GnRH neurons were detected within global-CREM KO $\left(F_{(5,48)}=10.7, p=0.001\right)$ and $G n R H$-CREB KO/ global-CREM KO $\left(F_{(5,48)}=10.7, p=0.0004\right)$ animals compared with control $C R E M^{+/+}$and $C R E B^{\text {loxP/loxP }}$ mice (Table 1).

The total numbers of GnRH neurons detected in control mice varied according to anatomical location (Table 1), as reported previously in mouse (Abrahám et al., 2003; 2005). The same patterns of GnRH immunoreactivity were detected within these brain regions between the control and GnRH-CREB KO, GnRHCREB KO/global-CREM KO, and global CREM KO brains (data not shown).
Table 1. GnRH neuron number in CREB mutant mice

\begin{tabular}{lrrll}
\hline Mouse line & \multicolumn{1}{c}{ MS } & \multicolumn{1}{c}{ rPOA } & AHA & $\begin{array}{l}\text { Total number of } \\
\text { GnRH neurons }\end{array}$ \\
\hline C57BL/6 & $6 \pm 0.3$ & $14 \pm 0.6$ & $3.3 \pm 0.3$ & $21.8 \pm 1.4$ \\
CREB ${ }^{\text {loxP/loxP }}$ & $6.3 \pm 0.3$ & $12.6 \pm 0.5$ & $3.4 \pm 0.4$ & $21.7 \pm 0.6$ \\
GnRH-CREB K0 & $6.9 \pm 0.2$ & $12.6 \pm 0.4$ & $3.3 \pm 0.3$ & $21.5 \pm 0.9$ \\
CREM $+/+$ & $5 \pm 0.3$ & $13.3 \pm 0.4$ & $3.5 \pm 0.3$ & $18.9 \pm 1$ \\
Global CREM K0 & $6.1 \pm 0.2$ & $15.1 \pm 0.6$ & $4.3 \pm 0.4$ & $25.9 \pm 0.6^{* *}$ \\
GnRH-CREB K0/global CREM KO & $8 \pm 0.4^{*}$ & $15 \pm 0.6$ & $6.1 \pm 0.2^{*}$ & $28.9 \pm 0.5^{* * *}$ \\
\hline
\end{tabular}

The numbers of GnRH neurons in the MS, in the rPOA, and at the level of the AHA are shown. GnRH neurons per section per region and the total number of $\mathrm{GnRH}$ neurons in MS, rPOA, and AHA were examined for each of the six genotypes. The table shows the means ( + SEM); $n=7-14$.

${ }^{*} p<0.05 ;{ }^{* *} p<0.01 ;{ }^{* * *} p<0.001$ (ANOVA with Tukey's post hoc test).
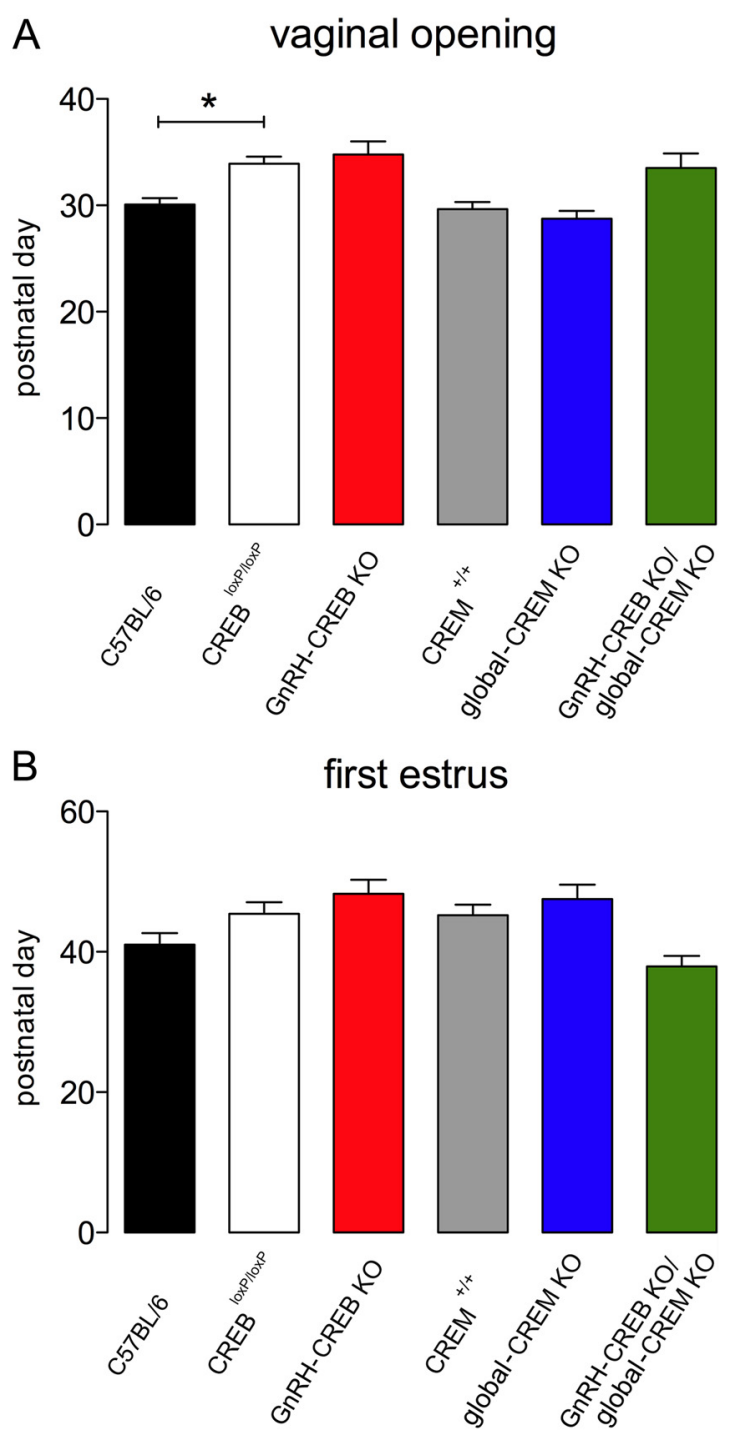

Figure 2. $\boldsymbol{A}, \boldsymbol{B}$, Puberty onset in CREB mutant mice. Vaginal opening $(\boldsymbol{A})$ and first estrus $(\boldsymbol{B})$ in transgenic and control mice. The mean ( + SEM) days of vaginal opening and first estrus are given for each of the six genotypes ( $n=8-14){ }^{*} p<0.05$ (ANOVA with Tukey's post hoc test).

\section{Puberty onset is normal in CREB mutant mice}

An increase in $\mathrm{GnRH}$ neuronal activity is required for initiation of puberty during sexual development (Terasawa and Fernandez, 2001). To disclose whether the puberty was affected in GnRHCREB mutant mice, the puberty onset was detected in those animals. Vaginal opening occurred at the same age in control and knock-out mice (Fig. 2A). Similarly, no differences were detected 

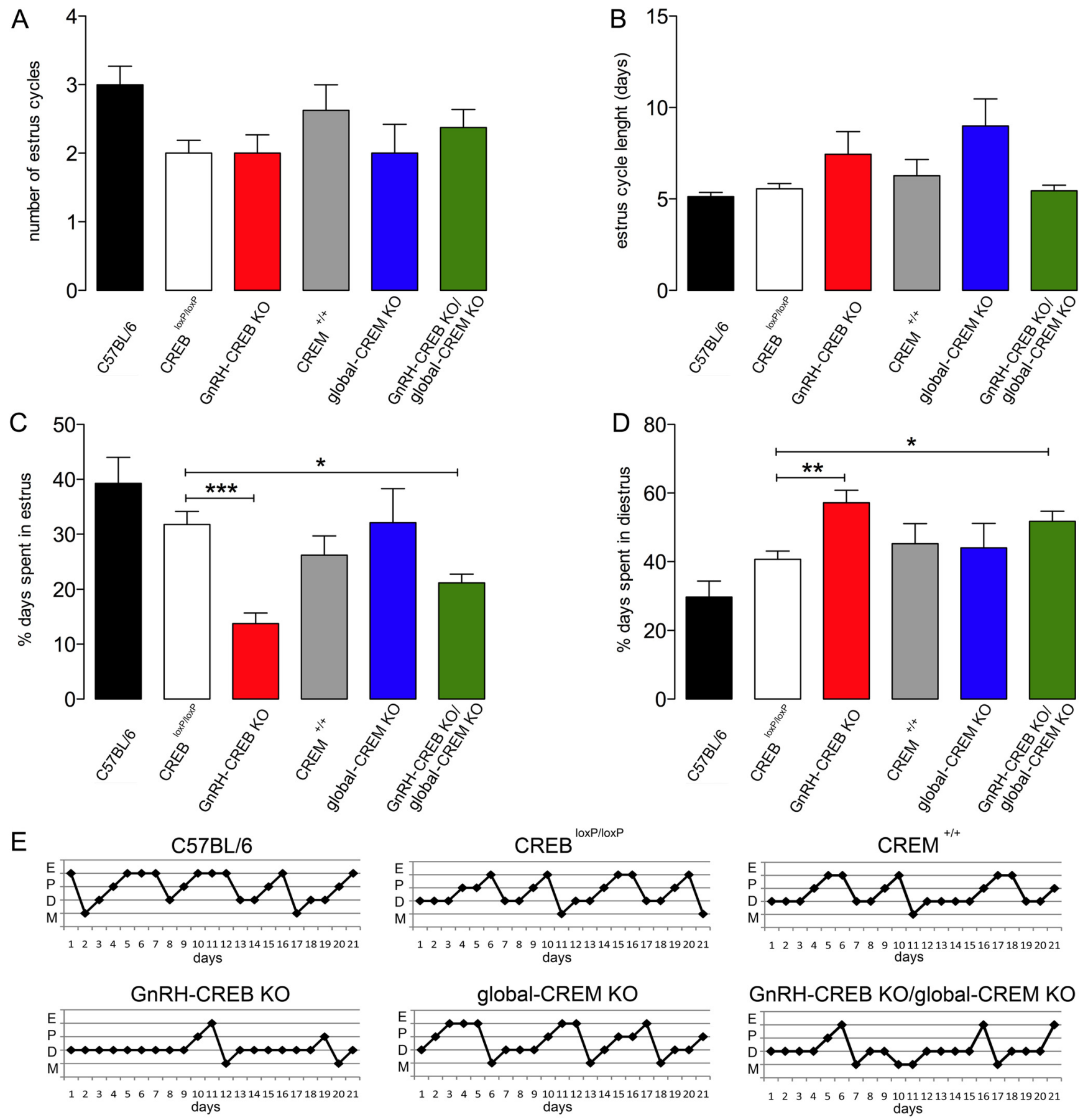

Figure 3. Abnormal estrus cyclicity in CREB knock-out mice. $\boldsymbol{A}-\boldsymbol{D}$, The number of cycles $(\boldsymbol{A})$, cycle length $(\boldsymbol{B})$, and percentage of time spent in estrus $(\boldsymbol{C})$ and diestrus $(\boldsymbol{D})$ in $(R E B$ mutant mice. $\boldsymbol{E}$, Representative estrus cycle profiles (for individual mice over a $21 \mathrm{~d}$ period) demonstrating the alterations in estrus cyclicity in CREB KO mice compared with controls. Both control and mutant mice show clearly distinguishable estrus cycle phases and proestrus-metestrus intermediate phases at similar frequency. The histograms show the means ( + SEM) for each of the six genotypes; $n=$ $8-16 .{ }^{*} p<0.05 ;{ }^{* *} p<0.01 ;{ }^{* *} p<0.001$ (ANOVA with Tukey's post hoc test). E, Estrus; P, proestrus; D, diestrus; M, metestrus.

between the day of first estrus in control and knock-out mice (Fig. 2 B). Vaginal opening, but not first estrus, was delayed by $\sim 3$ $\mathrm{d}$ in control $C R E B^{\text {loxp/loxP }}$ mice, compared with wild-type C57BL/6 mice $\left(F_{(5,78)}=8.2, p=0.03\right.$; Fig. $\left.2 A\right)$.

Estrus cyclicity is disrupted in CREB mutant mice

After puberty, the GnRH neurons plays pivotal role in the regulation of estrus cycle. Accordingly, estrus cyclicity was evaluated using vaginal smears for a period of 3 weeks. These data showed that the number of complete cycles and length of each cycle was variable but not significantly different between mutant mice and controls (Fig. $3 A, B$ ). However, the percentage of time spent in diestrus and estrus within these cycles was significantly different. GnRH-CREB KO and GnRH-CREB KO/global-CREM KO mice experienced longer periods of diestrus $\left(F_{(5,42)}=7.6\right.$; GnRHCREB KO, $p=0.003$; GnRH-CREB KO/global-CREM KO, $p=$ $0.01)$ and spent significantly less time in estrus $\left(F_{(5,42)}=5.7\right.$; GnRH-CREB KO, $p=0.0004 ; G n R H-C R E B$ KO/global-CREM $K O, p=0.03$ ) than controls (Fig. 3C,D). Representative estrus cycle profiles demonstrating these alterations are presented in 


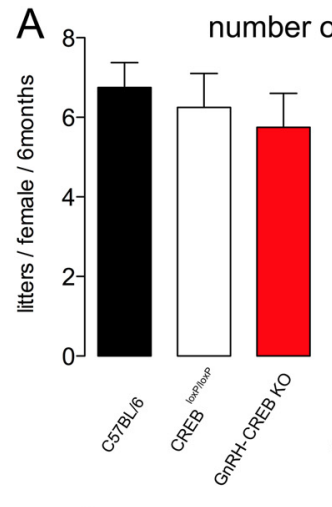

C

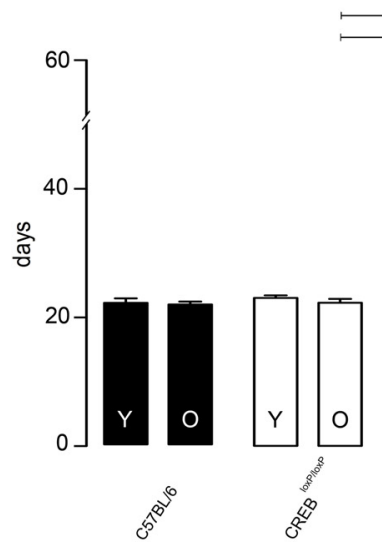

B

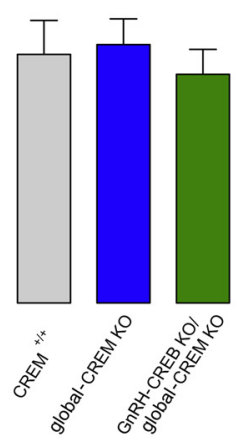

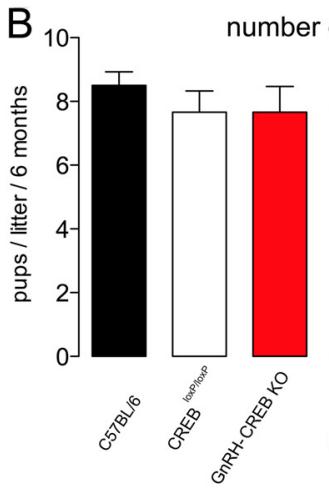

umber of pups

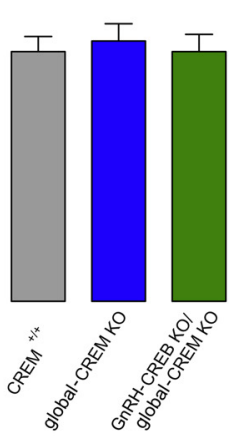

elivery interval in young and old mice

had doubled in GnRh-CREB-KO $\left(F_{(5,30)}=\right.$ 10.7, $p=0.003)$ and GnRH-CREB KO/ global-CREM KO animals $\left(F_{(5,30)}=10.7\right.$, $p=0.0001)$ (Fig. 4C).

Abnormal estrogen negative feedback in CREB mutant female mice

Estrogen negative feedback on GnRH neurons is known to be critical for maintaining normal estrus cyclicity and fecundity. To assess the estrogen action on $\mathrm{GnRH}$ neurons, an estrogen negative feedback protocol was applied where the LH levels were measured at basal conditions, after ovariectomy and $3 \mathrm{~h}$ of $\mathrm{E} 2$ administration.

The basal serum LH levels of GnRHCREB KO/global-CREM KO mice were significantly lower than basal LH levels of CREB $B^{\text {loxPlloxP }}$ (control), GnRH-CREB $\mathrm{KO}, \mathrm{CREM}^{+/+}$, and global-CREM KO mice in diestrus (Fig. 5).

Ovariectomy induced a fourfold increase in the LH levels in C57BL/6, $C R E B^{\text {loxPloxP }}$, GnRH-CREB KO, CREM ${ }^{+/+}$, and global CREM KO mice (Fig. 5). In contrast, the LH rise in GnRH-CREB KO/ global-CREM KO mutants was significantly attenuated $\left(F_{(5,78)}=6.6, p=\right.$ 0.0001; Fig. $5 A, C)$.

Whereas E2 treatment suppressed LH levels in C57BL/6, CREB $B^{\text {loxP/loxP }}$, $\mathrm{CREM}^{+/+}$, global-CREM KO, and GnRHCREB KO/global-CREM KO mice, it was significantly less effective in GnRH-CREB $K O$ mice $\left(F_{(5,42)}=6, p=0.002\right.$; Fig. $\left.5 A\right)$.

Figure 3E. The estrus cycles (Fig. 3C-E) of global CREM KO mice were not different from those of controls.

\section{Impaired fecundity of CREB mutant mice}

To demonstrate whether the disrupted estrus cyclicity resulted in any change in fertility, a fecundity test was performed evaluating birth, number of pups, and delivery intervals. No significant differences were detected between control and GnRH-CREB KO or GnRH-CREB KO/global-CREM KO mice in terms of the number of delivered litters or pups per litter delivered during the first 6 months of the testing period (Fig. 4A,B). Fifty percent of the tested global-CREM KO mutant females were infertile $(n=6)$, while the fertile global CREM KO females produced a normal number of litters and a normal number of pups per litter compared to control mice. To investigate the time between the deliveries of consecutive litters, delivery intervals were calculated. During the first 6 months of testing, no significant differences were detected between control and GnRH-CREB KO, GnRHCREB KO/global-CREM KO, or fertile global-CREM KO mice in terms of the delivery interval.

However, after 6 months of age ( $6.3 \pm 0.2$ months; $n=3)$ the fertile global-CREM KO females stopped producing litters. At approximately 9 months of age, GnRH-CREB KO $(8 \pm 0.2$ months; $n=6)$ and GnRH-CREB KO/global-CREM KO (9.5 \pm $0.8 ; n=6$ ) mice also completely stopped producing litters, while controls remained fertile delivering litters until the experiment was discontinued. After 6 month of age, the delivery interval
In $\mathrm{GnRH}$-CREB KO mice, E2 induced a $36 \pm 13 \%$ decrease in $\mathrm{LH}$ levels compared to an $83 \pm 7 \%$ decrease in $C R E B^{\text {loxP/loxP }}$ controls $\left(F_{(5,42)}=5, p=0.002\right.$; Fig. $\left.5 A, D\right)$.

\section{Decreased somatic spine density of GnRH neurons in CREB} knock-out mice

Previous work has shown that the density of spines on the soma of GnRH neurons is regulated by estrogen (Chan et al., 2011). As such, we examined here whether soma spine density was altered in GnRH-CREB KO mice.

$\mathrm{GnRH}$ immunofluorescence labeling on brain sections from intact female $C R E B^{\text {loxPlloxP }}$ and GnRH-CREB KO mice in diestrus revealed that deletion of CREB from GnRH neurons significantly alters somatic spine density in GnRH neurons of the rPOA (Fig. $6 A-C)$. GnRH-CREB KO mice demonstrated a significant decrease in GnRH somatic spine density $\left(F_{(2,15)}=34.95, p=0.002\right.$, $n=112 \mathrm{GnRH}$ neurons from five mice; Fig. $6 \mathrm{C})$ compared with CREB ${ }^{\text {loxP/loxP }}$ mice ( $n=129 \mathrm{GnRH}$ neurons from six mice). No significant differences were observed in GnRH soma circumference between control and GnRH-CREB KO mice (Fig. 6D). The number of spines per $\mathrm{GnRH}$ neuron also showed a significant decrease $\left(F_{(2,15)}=39.84, p=0.001\right.$; Fig. $\left.6 E\right)$ in GnRH-CREB KO mice compared to controls.

\section{Discussion}

We report here on the generation and reproductive phenotypes of mutant mouse models with different combinations of $\mathrm{GnRH}$ 
neuron-specific CREB and global CREM deletions. Our most important result is that mice with a GnRH neuron-specific CREB deletion, with or without global CREM knock-out, exhibit normal puberty, but have disordered estrous cycles and E2 negative feedback, show premature reproductive senescence, and exhibit a 50\% reduction in GnRH somatic spine density. In addition, we note reproductive deficits of global-CREM KO mice and the interesting observation that the numbers of GnRH neurons in the brain are increased following global CREM deletion.

To define the role of CREB in GnRH neurons we generated a GnRH neuronspecific CREB mutant mouse line using a Cre-LoxP conditional mutagenesis strategy. We show here that crossing this GnRH-Cre mouse with the CREB $B^{\text {loxP/loxP }}$ strain results in a complete abolition of CREB expression in all GnRH neurons. It remains possible that this strategy will also delete CREB from the population of lateral septal cells that express GnRH in the perinatal period (Skinner et al., 2009). The functions of these lateral septal cells are unknown, but they are very unlikely to be involved in control of the hypothalamicpituitary-gonadal axis.

One unexpected phenotype noted in the global-CREM KO mouse was a small but significant $\sim 30 \%$ increase in the number of GnRH neurons. This may arise from either enhanced GnRH protein expression in GnRH neurons, making more cells detectable with immunohistochemistry, or from a real increase in the number of $\mathrm{GnRH}$ neurons in the brain. The increase in GnRH neuron number was not restricted to one part of the GnRH neuron continuum within the MS-rPOA-AHA, suggesting that it is probably not a defect in the timing or sequence of migration (Jasoni et al., 2009).

Within the nervous system, CREB is known to be critical for many processes ranging from cell survival through to the maintenance of long-term memory (Silva et al., 1998; Finkbeiner, 2000; Mantamadiotis et al., 2002). Interestingly CREB deletion from an early embryonic time point appears to have relatively little effect on GnRH neurons. While they exhibit some reproductive deficits, the GnRH neurons continue to synthesize $\mathrm{GnRH}$ and are capable of supporting normal levels of fertility when young. Previous studies have shown that the great majority (at least $65 \%$ ) of GnRH neurons need to be deleted before a reproductive phenotype appears (Herbison et al., 2008). This indicates that at least $35 \%$ of GnRH neurons in CREB/CREM mutant female mice are viable.

We found that puberty is normal in GnRH-CREB KO mice with and without global-CREM KO. As adults, however, GnRHCREB KO mice with and without global-CREM KO exhibited estrus cycles of normal length but with greater time spent in diestrus and less in estrus. A similar disassociation in dysfunction between the first and latter ovulations has been found in GNR23 mice that have a markedly reduced number of GnRH neurons (Herbison et al., 2008).

This disordered estrus cyclicity did not, however, impact upon fecundity as, in the first 6 months, the numbers of litters generated by mutant mice were slightly but not significantly decreased compared to their controls. These observations indicate that GnRH-CREB KO mutant mice exhibit normal ovulation despite the disturbed negative feedback during this period. However, altered GnRH/LH output in GnRH-CREB KO/global-CREM KO mutant mice may cause subtle but destabilizing changes in LH secretion able to disrupt the normal homeostasis of the estrus cyclicity.

After 6 months of age, we began to notice marked changes in fecundity. By 8 to 9 months of age, all GnRH-CREB KO mice with and without global-CREM KO had stopped producing litters. These observations demonstrate that the absence of CREB in GnRH neurons results in premature reproductive aging. Several studies indicate that changes in GnRH neuron function, in particular their ability to generate the preovulatory $\mathrm{GnRH} / \mathrm{LH}$ surge, are responsible for reproductive senescence in rodents (Nass et al., 1984; Lu et al., 1985; Matt et al., 1987; Gore et al., 2000). Modulation of GnRH neurons is an initial factor in reproductive senescence with a greater driving role in rodents and a lesser role in primates, including humans (Hall et al., 2000; Gill et al., 2002; Shaw et al., 2009; Kermath and Gore, 2012).

It has been suggested that the negative feedback actions of E2 occur in a multimodal manner involving rapid and direct actions on the GnRH neuron, transsynaptic effects, and GnRH neuronglial remodeling (Herbison 1998; Petersen et al., 2003; Prevot et al., 2010; Handa et al., 2011). Previous studies have shown that E2 injections can quickly reduce serum LH levels (in $<30 \mathrm{~min}$ ) (Yamaji et al., 1972; Negro-Vilar et al., 1973) and portal blood GnRH (Sarkar and Fink, 1980), but the rapidity of this E2 effect has been difficult to associate with a genomic mode of E2 action (Barnea and Gorski, 1970; Lagrange et al., 1995). Furthermore, recent studies found that $10 \mathrm{pM}$ E2, a physiological concentration 

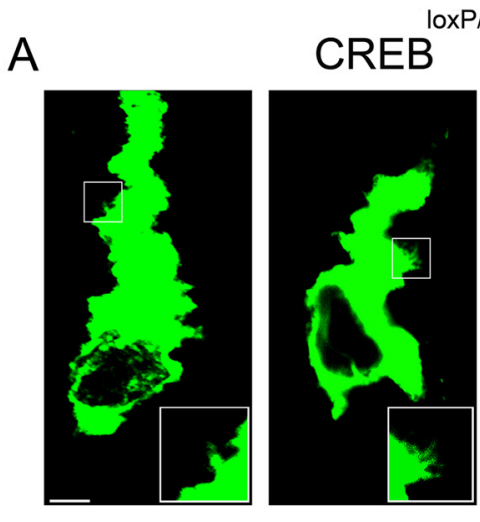

loxP/loxP

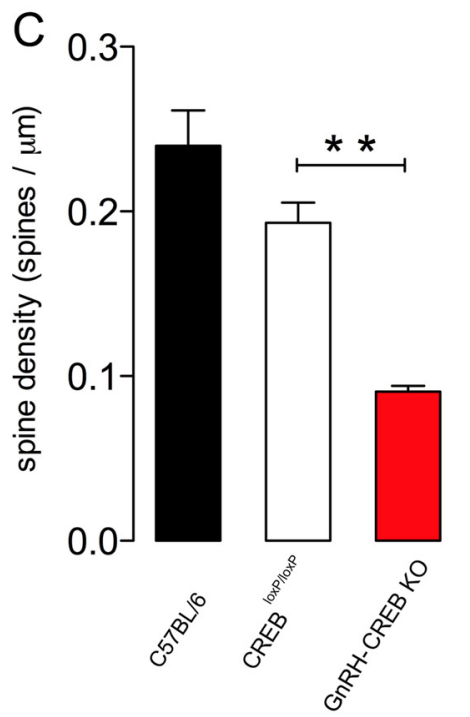

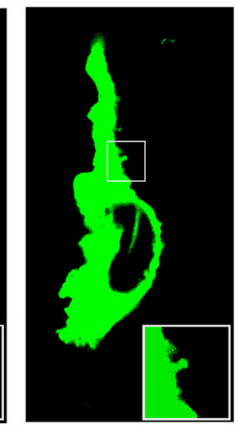
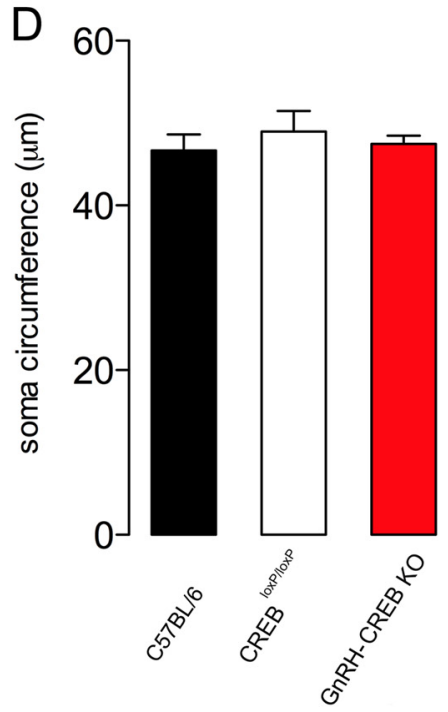

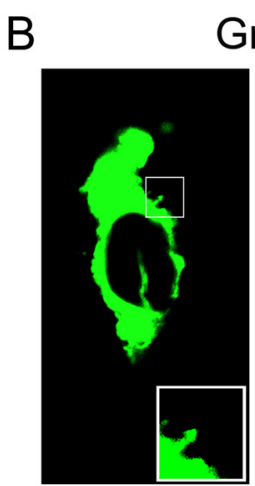

GnRH-CREB KO
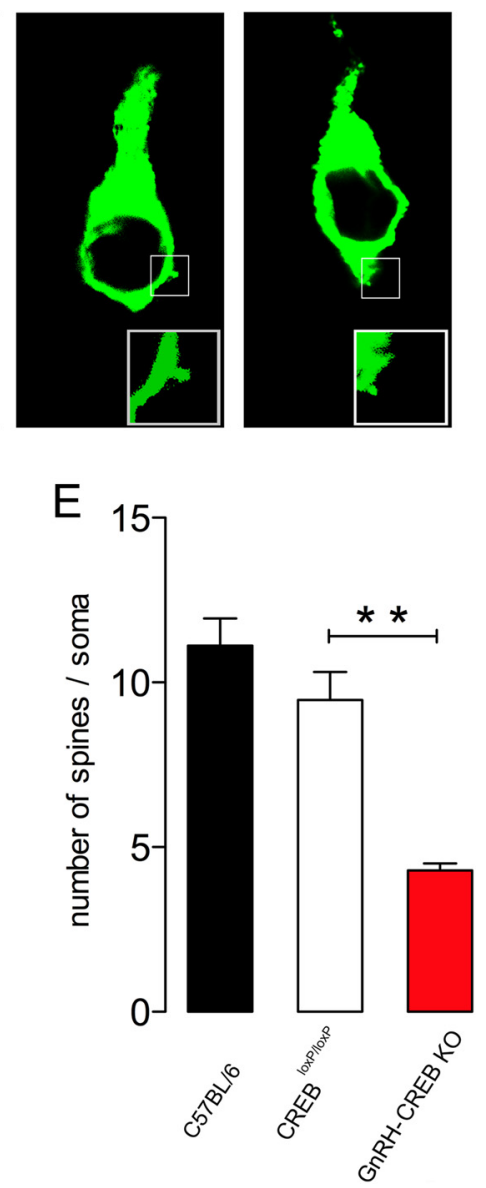

Figure 6. Somatic spine density of GnRH neurons in CREB knock-out mice. $\boldsymbol{A}, \boldsymbol{B}$, Confocal stacks ( $400 \mathrm{~nm}$ optical thickness) of GnRH-immunolabeled neurons from $C R E B^{\text {loxP/loxP }}$ ( $\boldsymbol{A}$ ) and $G n R H$-CREB $K O(B)$ mice. Insets, Typical somatic spines are shown in confocal stacks from corresponding white boxes in $\mathbf{G n R H}$ neurons in $\boldsymbol{A}$ and $\boldsymbol{B}$. Scale bar, $5 \boldsymbol{\mu m}$. $\boldsymbol{C}-\boldsymbol{E}$, Spine densities for the somata $(\boldsymbol{C})$, soma circumferences $(\boldsymbol{D})$, and numbers of spines on GnRH neurons $(\boldsymbol{E})$ of control $\left(C 57 \mathrm{BL} / 6,\left(\mathrm{CREB} B^{\text {loxP/loxP }}\right)\right.$ and GnRH-CREB KO mice. The histograms show the means $(+\mathrm{SEM}) ; n=4-6$. $^{* *} p<0.01(\mathrm{ANOVA}$ with Tukey's post hoc test).

during negative feedback, rapidly inhibited GnRH neuron firing (Chu et al., 2009). Another piece of evidence for nonclassical mechanisms in estrogen negative feedback comes from $\operatorname{ER} \alpha$ mutant mice with a mutated estrogen response element-binding domain where basal LH levels are intermediate between intact and ovariectomized normal LH levels (Glidewell-Kenney et al., 2007; Zhao et al., 2009), suggesting an involvement of both classical and non-estrogen response element (ERE)-dependent mechanisms. Our previous work using ER KO mice also found that rapid E2 action is unable to suppress LH secretion in ER single and double knock-out mice, demonstrating that classical ERs are essential for the rapid inhibitory $\mathrm{E} 2$ actions and for normal negative feedback (Abrahám et al., 2003, 2004; Couse et al., 2003; Dorling et al., 2003; Herbison 2009). Recent data suggest the predominance of $\mathrm{ER} \alpha$ in the negative feedback mechanism, with a possible role of both direct and indirect $\mathrm{ER} \beta$-mediated actions on GnRH neurons (Handa et al., 2011).

The experiments reported here add to this complex dynamic of E2 actions by showing the physiological importance of CREB within $\mathrm{GnRH}$ neurons in this process. Our previous studies showed that CREB within GnRH neurons is phosphorylated rapidly by E2 (Abrahám et al., 2003), indicating that, despite CREB's established role in regulating gene transcription in a classical manner (Walton and Dragunow, 2000; Lonze and Ginty, 2002), it may also be involved in the rapid phase of E2 negative feedback. The negative feedback experiments performed in this study support this concept, as GnRH-CREB-deleted mice were unable to exhibit the full E2-evoked acute suppression of LH secretion. We interpret this as indicating that CREB in GnRH neurons is essential for one component of the acute E2 negative feedback response of GnRH neurons. It is possible that one instance where CREM may in fact be compensating for CREB loss in GnRH neurons is in the post-OVX LH rise, where the increment in $\mathrm{LH}$ levels was significantly suppressed in GnRH-CREB KO/globalCREM KO mice compared with GnRH-CREB only KOs. It seems clear that CREB is not the only signaling mechanism involved in E2 feedback. First, the acute suppression of LH by E2 still occurs in $G n R H$-CREB KO mice but is blunted in magnitude. Thus, other rapid actions of $\mathrm{E} 2$ through indirect transsynaptic or direct mechanisms (Lagrange et al., 1995; Romano et al., 2008; Chu et al., 2009; Zhao et al., 2009) are also likely to be in play. Second, we note that basal LH levels are within the normal range in intact GnRH-CREB KO mice, and the 1 week post-OVX increase in LH is normal. This indicates that rapid E2 actions through CREB can only represent one part of the negative feedback mechanism, although the diestrus-dominated estrous cycles of $G n R H$-CREB $\mathrm{KO}$ mice indicate some abnormality. 
Prior studies have shown that CREB mediates effects of E2 on dendritic remodeling and spine formation in the hippocampus (Murphy and Segal, 1997; Segal and Murphy, 2001). As E2 is known to regulate somatic spine density of GnRH neurons (Chan et al., 2011), we reasoned that CREB deletion may impact spine density in these cells. Indeed, we show here that CREB deletion results in a substantial 50\% decrease in GnRH neuron spine density. This observation suggests that one impact of deleting CREB in GnRH neurons is that of reduced spine density and likely reduced afferent input, and that this may underlie defective negative feedback in these cells.

In summary, we report here that CREB expressed by GnRH neurons is required for normal fertility. The use of cell-specific mutagenesis has been critical in allowing us to dissect the role of CREB specifically in GnRH neurons in vivo. Together with previous evidence that $\mathrm{E} 2$ rapidly phosphorylates CREB in GnRH neurons, we suggest that the negative feedback deficits encountered in GnRH-CREB KO mice result from defective acute E2 modulation of $\mathrm{GnRH}$ neurons that ultimately impact upon spine formation and altered afferent input. It is possible that the abnormal E2 feedback in these mice also contributes to their early reproductive senescence. These studies provide evidence for the physiological importance of rapid, nonclassical E2 actions within the brain and help define the mechanism of E2 negative feedback on GnRH neurons.

\section{References}

Abrahám IM, Herbison AE (2005) Major sex differences in non-genomic estrogen actions on intracellular signaling in mouse brain in vivo. Neuroscience 131:945-951.

Abrahám IM, Han SK, Todman MG, Korach KS, Herbison AE (2003) Estrogen receptor beta mediates rapid estrogen actions on gonadotropinreleasing hormone neurons in vivo. J Neurosci 23:5771-5777.

Abrahám IM, Todman MG, Korach KS, Herbison AE (2004) Critical in vivo roles for classical estrogen receptors in rapid estrogen actions on intracellular signaling in mouse brain. Endocrinology 145:3055-3061.

Barnea A, Gorski J (1970) Estrogen-induced protein. Time course of synthesis. Biochemistry 9:1899-1904.

Blendy JA, Kaestner KH, Weinbauer GF, Nieschlag E, Schütz G (1996) Severe impairment of spermatogenesis in mice lacking the CREM gene. Nature 380:162-165.

Boulware MI, Mermelstein PG (2009) Membrane estrogen receptors activate metabotropic glutamate receptors to influence nervous system physiology. Steroids 74:608-613.

Campbell RE, Han SK, Herbison AE (2005) Biocytin filling of adult gonadotropin-releasing hormone neurons in situ reveals extensive, spiny, dendritic processes. Endocrinology 146:1163-1169.

Campbell RE, Ducret E, Porteous R, Liu X, Herde MK, Wellerhaus K, Sonntag S, Willecke K, Herbison AE (2011) Gap junctions between neuronal inputs but not gonadotropin-releasing hormone neurons control estrous cycles in the mouse. Endocrinology 152:2290-2301.

Chan H, Prescott M, Ong Z, Herde MK, Herbison AE, Campbell RE (2011) Dendritic spine plasticity in gonadatropin-releasing hormone $(\mathrm{GnRH})$ neurons activated at the time of the preovulatory surge. Endocrinology 152:4906-4914.

Chu Z, Andrade J, Shupnik MA, Moenter SM (2009) Differential regulation of gonadotropin-releasing hormone neuron activity and membrane properties by acutely applied estradiol: dependence on dose and estrogen receptor subtype. J Neurosci 29:5616-5627.

Couse JF, Yates MM, Walker VR, Korach KS (2003) Characterization of the hypothalamic-pituitary-gonadal axis in estrogen receptor (ER) Null mice reveals hypergonadism and endocrine sex reversal in females lacking ERalpha but not ERbeta. Mol Endocrinol 17:1039-1053.

Dewing P, Boulware MI, Sinchak K, Christensen A, Mermelstein PG, Micevych P (2007) Membrane estrogen receptor-alpha interactions with metabotropic glutamate receptor la modulate female sexual receptivity in rats. J Neurosci 27:9294-9300.

Dorling AA, Todman MG, Korach KS, Herbison AE (2003) Critical role for estrogen receptor alpha in negative feedback regulation of gonadotropin- releasing hormone mRNA expression in the female mouse. Neuroendocrinology 78:204-209.

Finkbeiner S (2000) CREB couples neurotrophin signals to survival messages. Neuron 25:11-14.

Gill S, Sharpless JL, Rado K, Hall JE (2002) Evidence that GnRH decreases with gonadal steroid feedback but increases with age in postmenopausal women. J Clin Endocrinol Metab 87:2290-2296.

Glidewell-Kenney C, Hurley LA, Pfaff L, Weiss J, Levine JE, Jameson JL (2007) Nonclassical estrogen receptor alpha signaling mediates negative feedback in the female mouse reproductive axis. Proc Natl Acad Sci U S A 104:8173-8177.

Gore AC, Oung T, Yung S, Flagg RA, Woller MJ (2000) Neuroendocrine mechanisms for reproductive senescence in the female rat: gonadotropinreleasing hormone neurons. Endocrine 13:315-323.

Hall JE, Lavoie HB, Marsh EE, Martin KA (2000) Decrease in gonadotropinreleasing hormone $(\mathrm{GnRH})$ pulse frequency with aging in postmenopausal women. J Clin Endocrinol Metab 85:1794-1800.

Handa RJ, Ogawa S, Wang JM, Herbison AE (2011) Roles for oestrogen receptor $\beta$ in adult brain function. J Neuroendocrinol 24:160-173.

Herbison AE (1998) Multimodal influence of estrogen upon gonadotropinreleasing hormone neurons. Endocr Rev 19:302-330.

Herbison AE (2006) Physiology of the GnRH neuronal network. In: Physiology of reproduction, Ed 3 (Neill Ka, ed), pp 1415-1482. San Diego: Academic.

Herbison AE (2009) Rapid actions of oestrogen on gonadotropin-releasing hormone neurons; from fantasy to physiology? J Physiol 587:5025-5030.

Herbison AE, Porteous R, Pape JR, Mora JM, Hurst PR (2008) Gonadotropinreleasing hormone neuron requirements for puberty, ovulation, and fertility. Endocrinology 149:597-604.

Jasoni CL, Porteous RW, Herbison AE (2009) Anatomical location of mature GnRH neurons corresponds with their birthdate in the developing mouse. Dev Dyn 238:524-531.

Kelly MJ, Rønnekleiv OK (2009) Control of CNS neuronal excitability by estrogens via membrane-initiated signaling. Mol Cell Endocrinol 308:17-25.

Kelly MJ, Moss RL, Dudley CA (1976) Differential sensitivity of preopticseptal neurons to microelectrophoresed estrogen during the estrous cycle. Brain Res 114:152-157.

Kermath BA, Gore AC (2012) Neuroendocrine control of the transition to reproductive senescence: lessons learned from the female rodent model. Neuroendocrinology, in press.

Lagrange AH, Rønnekleiv OK, Kelly MJ (1995) Estradiol-17 beta and muopioid peptides rapidly hyperpolarize GnRH neurons: a cellular mechanism of negative feedback? Endocrinology 136:2341-2344.

Lonze BE, Ginty DD (2002) Function and regulation of CREB family transcription factors in the nervous system. Neuron 35:605-623.

Lu JK, LaPolt PS, Nass TE, Matt DW, Judd HL (1985) Relation of circulating estradiol and progesterone to gonadotropin secretion and estrous cyclicity in aging female rats. Endocrinology 116:1953-1959.

Mantamadiotis T, Lemberger T, Bleckmann SC, Kern H, Kretz O, Martin Villalba A, Tronche F, Kellendonk C, Gau D, Kapfhammer J, Otto C, Schmid W, Schütz G (2002) Disruption of CREB function in brain leads to neurodegeneration. Nat Genet 31:47-54.

Matt DW, Coquelin A, Lu JK (1987) Neuroendocrine control of luteinizing hormone secretion and reproductive function in spontaneously persistent-estrous aging rats. Biol Reprod 37:1198-1206.

McDevitt MA, Glidewell-Kenney C, Jimenez MA, Ahearn PC, Weiss J, Jameson JL, Levine JE (2008) New insights into the classical and non-classical actions of estrogen: evidence from estrogen receptor knock-out and knock-in mice. Mol Cell Endocrinol 290:24-30.

McNulty S, Schurov IL, Sloper PJ, Hastings MH (1998) Stimuli which entrain the circadian clock of the neonatal Syrian hamster in vivo regulate the phosphorylation of the transcription factor CREB in the suprachiasmatic nucleus in vitro. Eur J Neurosci 10:1063-1072.

Micevych P, Dominguez R (2009) Membrane estradiol signaling in the brain. Front Neuroendocrinol 30:315-327.

Moenter SM, Chu Z (2012) Rapid nongenomic effects of oestradiol on gonadotrophin-releasing hormone neurones. J Neuroendocrinol 24:117-121.

Moenter SM, Chu Z, Christian CA (2009) Neurobiological mechanisms underlying oestradiol negative and positive feedback regulation of 
gonadotrophin-releasing hormone neurones. J Neuroendocrinol 21:327-333.

Murphy D, Segal M (1997) Morphological plasticity of dendritic spines in central neurons is mediated by activation of cAMP response element binding protein. Proc Natl Acad Sci U S A 94:1482-1487.

Nass TE, LaPolt PS, Judd HL, Lu JK (1984) Alterations in ovarian steroid and gonadotrophin secretion preceding the cessation of regular oestrous cycles in ageing female rats. J Endocrinol 100:43-50.

Negro-Vilar A, Orias R, McCann SM (1973) Evidence for a pituitary site of action for the acute inhibition of LH release by estrogen in the rat. Endocrinology 92:1680-1684.

Nilsson S, Mäkelä S, Treuter E, Tujague M, Thomsen J, Andersson G, Enmark E, Pettersson K, Warner M, Gustafsson JA (2001) Mechanisms of estrogen action. Physiol Rev 81:1535-1565.

Paxinos G, Franklin FK (2000) The mouse brain in stereotaxic coordinates, Ed 2. San Diego: Academic.

Petersen SL, Ottem EN, Carpenter CD (2003) Direct and indirect regulation of gonadotropin-releasing hormone neurons by estradiol. Biol Reprod 69:1771-1778.

Prevot V, Hanchate NK, Bellefontaine N, Sharif A, Parkash J, Estrella C, Allet C, de Seranno S, Campagne C, de Tassigny X, Baroncini M (2010) Function-related structural plasticity of the GnRH system: a role for neuronal-glial-endothelial interactions. Front Neuroendocrinol 31:241-258.

Rizwan MZ, Poling MC, Corr M, Cornes PA, Augustine RA, Quennell JH, Kauffman AS, Anderson GM (2012) RFamide-related peptide-3 receptor gene expression in $\mathrm{GnRH}$ and kisspeptin 1 neurons and GnRHdependent mechanism of action. Endocrinology, in press.

Romanò N, Lee K, Abrahám IM, Jasoni CL, Herbison AE (2008) Nonclassical estrogen modulation of presynaptic GABA terminals modulates calcium dynamics in gonadotropin-releasing hormone neurons. Endocrinology 149:5335-5344.

Rudolph D, Tafuri A, Gass P, Hämmerling GJ, Arnold B, Schütz G (1998) Impaired fetal $\mathrm{T}$ cell development and perinatal lethality in mice lacking the cAMP response element binding protein. Proc Natl Acad Sci U S A 95:4481-4486.
Sarkar DK, Fink G (1980) Luteinizing hormone releasing factor in pituitary stalk plasma from long-term ovariectomized rats: effects of steroids. J Endocrinol 86:511-524.

Segal M, Murphy D (2001) Estradiol induces formation of dendritic spines in hippocampal neurons: functional correlates. Horm Behav 40:156-159.

Shaw ND, Srouji SS, Histed SN, McCurnin KE, Hall JE (2009) Aging attenuates the pituitary response to gonadotropin-releasing hormone. J Clin Endocrinol Metab 94:3259-3264.

Silva AJ, Kogan JH, Frankland PW, Kida S (1998) CREB and memory. Annu Rev Neurosci 21:127-148.

Skinner DC, Albertson AJ, Navratil A, Smith A, Mignot M, Talbott H, Scanlan-Blake N (2009) Effects of gonadotrophin-releasing hormone outside the hypothalamic-pituitary-reproductive axis. J Neuroendocrinol 21:282-292.

Soriano P (1999) Generalized lacZ expression with the ROSA26 Cre reporter strain. Nat Genet 21:70-71.

Srinivas S, Watanabe T, Lin CS, William CM, Tanabe Y, Jessell TM, Costantini F (2001) Cre reporter strains produced by targeted insertion of EYFP and ECFP into the ROSA26 locus. BMC Dev Biol 1:4.

Terasawa E, Fernandez DL (2001) Neurobiological mechanisms of the onset of puberty in primates. Endocr Rev 22 111-151.

Vasudevan N, Pfaff DW (2008) Non-genomic actions of estrogens and their interaction with genomic actions in the brain. Front Neuroendocrinol 29:238-257.

Walton MR, Dragunow I (2000) Is CREB a key to neuronal survival? Trends Neurosci 23:48-53.

Yamaji T, Dierschke DJ, Bhattacharya AN, Knobil E (1972) The negative feedback control by estradiol and progesterone of LH secretion in the ovariectomized rhesus monkey. Endocrinology 90:771-777.

Yoon H, Enquist LW, Dulac C (2005) Olfactory inputs to hypothalamic neurons controlling reproduction and fertility. Cell 123:669-682.

Zhao Z, Park C, McDevitt MA, Glidewell-Kenney C, Chambon P, Weiss J, Jameson JL, Levine JE (2009) p21-Activated kinase mediates rapid estradiol-negative feedback actions in the reproductive axis. Proc Natl Acad Sci U S A 106:7221-7226. 